\title{
Vemurafenib-Induced Pulmonary Injury
}

\author{
Laurenz Schmitt Tamara Schumann Christoph Löser Edgar Dippel
}

Department of Dermatology, Klinikum Ludwigshafen, Skin Cancer Center Rheinpfalz, Germany

\section{Keywords}

Vemurafenib - BRAF inhibitor · Pneumonia .

Lung injury · Inflammation - Side effects .

Melanoma $\cdot$ Pulmonary toxicity

\section{To the Editor:}

For patients with malignant melanoma, in non-resectable stage III or stage IV and showing evidence of oncogenetic BRAF mutation, therapy with the selective tyrosine kinase inhibitor vemurafenib is the state of the art. In phase 1,2, and 3 clinical trials vemurafenib was associated with consistent efficacy and improved survival [1-3]. Multiple cutaneous side effects like rash, arthralgia, photosensitivity, and keratoacanthoma-like lesions have been reported [4].

We report the case of a 48-year-old woman with metastatic melanoma under therapy with vemurafenib, who presented with bipulmonary infiltrates mimicking atypical pneumonia (fig. 1A). Pulmonary symptoms with sporadic dry coughing and an elevated temperature of $37.5^{\circ} \mathrm{C}$ developed at week 10 after initiation of treatment with a standard dose of vemurafenib, $960 \mathrm{mg}$ twice daily. C-reactive protein was initially elevated at $4.6 \mathrm{mg} / \mathrm{dl}$ (normal < 0.5$)$ up to a peak value of $7.0 \mathrm{mg} / \mathrm{dl}$ after 3 days; procalcitonin levels remained at $0.1 \mathrm{ng} /$ $\mathrm{ml}(<0.1)$ and leukocyte count at 9,900/nl (4,500-11,000); and oxygen saturation was $98 \%$ spontaneously. Bronchoalveolar lavage (BAL) was conducted twice, but indicated no signs for a viral, bacterial or fungal origin of the infiltrates. Serum antibodies were negative for relevant pathogens (Aspergillus, Candida, Chlamydia, Legionella, cytomegalovirus and Mycoplasma). No additional medication was administered.

Due to the tentative diagnosis of an atypical bacterial pneumonia, oral treatment with levofloxacin $500 \mathrm{mg}$ once daily and clarithromycin $250 \mathrm{mg}$ twice daily was initiated over a course of 3 weeks, while treatment with vemurafenib was discontinued. Follow-up computed tomography scans showed a nearly complete remission of the infiltrations 6 days after discontinuation of vemurafenib therapy (fig. 1B). Vemurafenib was administered again at the standard dose (960 mg twice daily) for 2 weeks after withdrawal. 3 weeks after re-initiation of vemurafenib the lung infiltrations worsened again. Because of 2 surgical interventions (uterine metastatic bleeding and non-responding axillar lymph node metastasis) administration of vemurafenib had to be stopped, twice for 3 days in each case. During these, albeit short, treatment pauses the lung infiltrates regressed once again, confirming a causative correlation to vemurafenib treatment. Because of the good response of the target lesions, we decided to continue vemurafenib treatment but at a reduced dose of $720 \mathrm{mg}$ twice daily. Under this regimen, pulmonary infiltrates were no longer observed (fig. 2).
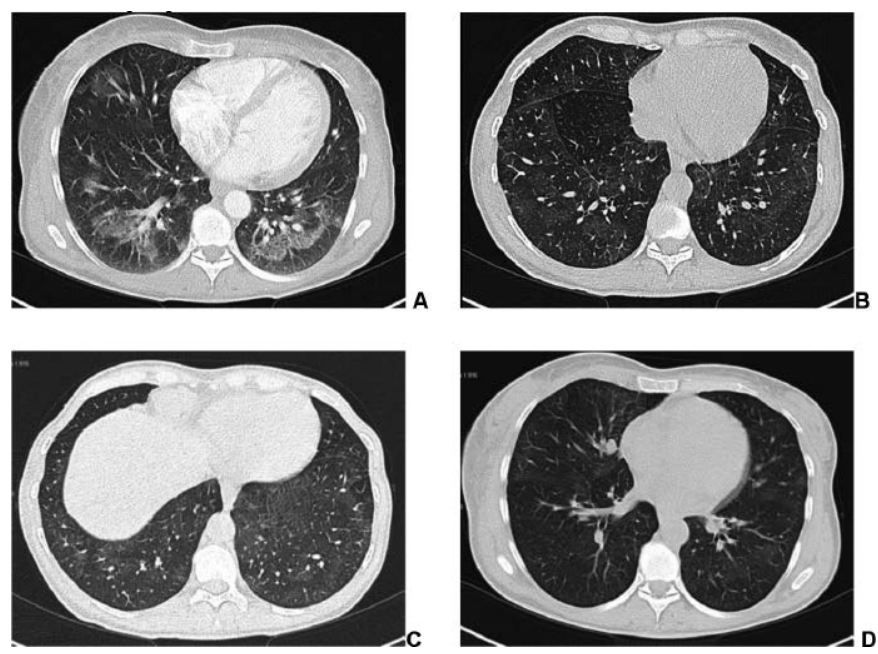

Fig. 1. A Thoracic chest CT scan with multiple bipulmonary infiltrates 10 weeks after begin of a therapy with vemurafenib. B Follow-up CT scan of the chest 6 days after discontinuation of vemurafenib, showing a regression of infiltrates. C Worsening of the pulmonary infiltrates 3 weeks after continuation of vemurafenib at a dose of $960 \mathrm{mg}$ twice daily. D Follow-up CT scan 3 days after discontinuation of vemurafenib.

\section{KARGER}

Fax +497614520714

Information@Karger.com

www.karger.com (c) 2013 S. Karger GmbH, Freiburg

0378-584X/13/03611-0685\$38.00/0

Accessible online at:

www.karger.com/onk
Dr. Laurenz L Schmitt

Klinikum Ludwigshafen

67063-Ludwigshafen, Germany

schmittl@klilu.de 


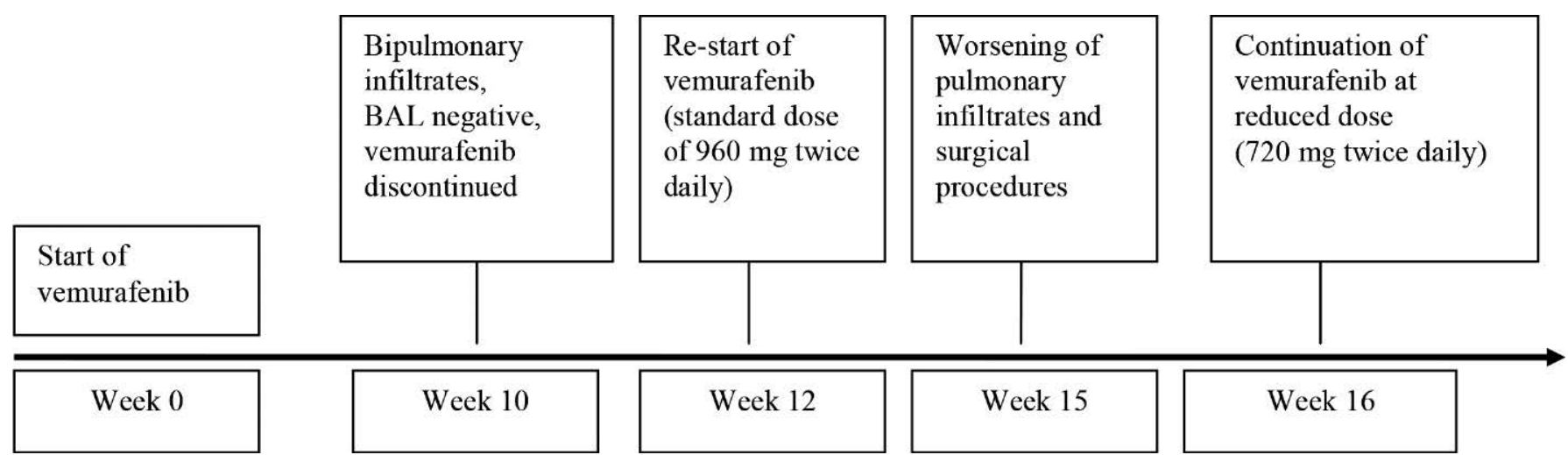

Fig. 2. Time course of the appearance of pulmonary infiltrates with vemurafenib treatment.

Chemotherapy-induced lung injury has been described previously. Multi-tyrosine kinase inhibitors like gefitinib and imatinib, given to patients for different oncological diseases such as advanced liver cancer, chronic myelogenous leukemia and gastrointestinal tumors, have been identified as risk factors for interstitial pneumonia [5, 6]. The large variety of tumors with proven selective BRAF mutations, such as anaplastic thyroid cancer or adenocarcinoma of the lung, indicate that treatment with selective BRAF inhibitors like vemurafenib may well play an increasing role in the treatment of these diseases in future [7, 8]. Programmed death-1 (PD-1) receptor antibodies have also recently been shown to be associated with pulmonary toxicity $[9,10]$. To our knowledge this is the first report of pulmonary injury associated with vemurafenib treatment. Since this problem is just emerging, and may even vary based upon nature of the underlying malignancy, we recommend that patients receiving vemurafenib should be monitored closely for lung toxicity.

\section{Disclosure Statement}

The authors declare no conflict of interests.

\section{References}

1 Chapman PB, Hauschild A, Robert C, et al.: Improved survival with vemurafenib in melanoma with BRAF V600E mutation. N Eng J Med 2011; 364:2507-2516.

2 Flaherty KT, Puzanov I, Kim KB, et al.: Inhibition of mutated, activated BRAF in metastatic melanoma. N Engl J Med 2010;363:809-819.

3 Sosman JA, Kim KB, Schuchter L, et al.: Survival in BRAF V600-mutant advanced melanoma treated with vemurafenib. N Engl J Med 2012;366: 707-714.
Oberholzer PA, Kee D, Dziunycz P, et al.: RAS mutations are associated with the development of cutaneous squamous cell tumors in patients treated with RAF inhibitors. J Clin Oncol 2012; 30:316-321.

5 Limper AH: Chemotherapy-induced lung disease. Clin Chest Med 2004;25:53-64.

6 6 Rosado MF, Donna E, Ahn YS: Challenging problems in advanced malignancy: Case 3. Imatinib mesylate-induced interstitial pneumonitis. J Clin Oncol 2003;21:3171-3173.
Gautschi O, Pauli C, Strobel K, et al.: A patient with BRAF V600E lung adenocarcinoma responding to vemurafenib. J Thorac Oncol 2012;7:e23-24.

8 Rosove MH, Peddi PF, Glaspy JA. BRAF V600E inhibition in anaplastic thyroid cancer. N Engl J Med 2013;368:684-685.

9 Topalian SL, Hodi FS, Brahmer JR, et al.: Safety, activity, and immune correlates of anti-PD-1 antibody in cancer. N Engl J Med 2012;366:2443-2454.

10 Hamid O, Robert C, Daud A, et al.: Safety and tumor responses with lambrolizumab (anti-PD-1) in melanoma. N Engl J Med 2013;369:134-144. 